\title{
Application of a Microseismic Method of Rock Burst Risk Assessment under Blasting Mining in Ashele Copper Mine
}

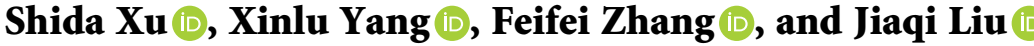 \\ Key Laboratory of Ministry of Education on Safe Mining of Deep Metal Mines, Northeastern University, Shenyang, \\ Liaoning 110819, China \\ Correspondence should be addressed to Shida Xu; xushida@mail.neu.edu.cn
}

Received 4 November 2021; Revised 30 December 2021; Accepted 18 January 2022; Published 21 February 2022

Academic Editor: Chengzhi Shi

Copyright $\odot 2022$ Shida Xu et al. This is an open access article distributed under the Creative Commons Attribution License, which permits unrestricted use, distribution, and reproduction in any medium, provided the original work is properly cited.

Rock burst is a violent release of energy stored in the rock mass, which has been the focus of metal mine engineers. It gradually becomes a serious threat to both the mine's workers and equipment. Rock burst risk assessment is a key issue in the prevention of rock burst. Based on the microseismic method for rock burst risk assessment that is used in tunnels, this paper presents a method of rock burst risk assessment for metal mines combining a simplified probability function and principal component analysis (PCA). Specifically, the size and details of key monitoring area and risk assessment units are determined according to the distribution of the fracture and driving stress during deep mining process. Based on the correlation analysis, six microseismic parameters are selected to be used for rock burst risk assessment. Simple linear functions are temporarily used to construct probability functions of each parameter before enough rock burst cases are collected. The method has been successfully used in the deep mining section of the Ashele Copper Mine (approximately $1000 \mathrm{~m}$ deep). Additionally, among various microseismic indicators, the energy release rate and cumulative energy are the greatest contributors to rock burst of different intensities. Therefore, the proposed method in this paper provides an important reference for the prevention and control of rock burst in metal mines.

\section{Introduction}

High stress usually occurs in deep underground engineering. When the actual stress exceeds the rock mass strength, some brittle failure may occur, accompanied with the release of a large quantity of energy [1-3]. This phenomenon is named rock burst. Rock burst have been observed in mines $[4,5]$, tunnels [6], hydraulic engineering projects $[7,8]$, and other forms of underground engineering projects and has become a worldwide problem. The number of rock burst cases is reported in the tunnels of Norway [9], in hydraulic engineering projects in China [10], and in the deep mines of China [11], South Africa [12], and Canada [13]. A rock burst may cause equipment damage, construction scheme delay, and even the loss of lives because of its violence [14-16]. Professor Fairhurst indicates that understanding and controlling rock burst is one of the greatest challenges of deep mining engineering safety [17]. Suorineni et al. [18] use a cancer metaphor for contemporary geological mechanics in deep mining to describe rock burst. Obviously, rock burst has become a common problem in deep mining.

Some rock burst risk assessment and warning methods have been reported, which include microseismic monitoring [19], infrared monitoring [20], seismic velocity tomography [21], and computed tomography technology [22], and a study was conducted on rock burst tendency [23]. As a result, many great theories and types of risk assessment indicators have been proposed by researchers based on energy, fracture, damage, and nonlinear theory [24-27]. In general, rock burst risk assessment methods can be divided into two types: one is performed before mining, and the other is performed during the mining process [28]. The former type pays attention to mining geology, ground stress, and the mechanical properties of the rock mass and provides a theoretical basis for the optimization of mining parameters, a supporting plan, and the prevention and control of 
rock burst $[29,30]$. The latter assesses rock burst risk dynamically according to detailed conditions and information gained from monitoring the mining process and then takes timely rock burst control measures. To some degree, the latter rock burst assessment method is more accurate than the former.

Over the past few decades, microseismic monitoring technology has gradually become the primary safety monitoring and risk assessment tool used for underground engineering projects in the world [31-36]. Many scholars presented risk assessment methods and rock burst indicators after studying the law of microseismicity in the process of construction [37]. For example, at the Mt Charlotte Mine, Poplawski [38] proposed departure indexing for rock burst hazard assessment to overcome the disadvantages of traditional method with only using one or two seismic parameters. Alcott et al. [39] discussed a method of using energy, apparent stress, and seismic moment criteria to identify the relevant events for microseismic hazard assessment. Tang and Xia [40] defined the rate of change of the ratio of the seismic stiffness in the nucleation region to that in surrounding region as the indicator of the rock burst prediction. Tang et al. [41] integrated microseismic monitoring and numerical simulation to improve the accuracy of rock burst prediction at Jinping II hydropower station. Zhou et al. [42] adopted heuristic algorithms like genetic algorithm, particle swarm optimization, and support vector machine to establish hybrid models to predict rock burst. Feng et al. [28] suggested a method for predicting various rock burst intensities and successfully targeted measures to reduce rock burst risk at the Jinping II hydropower project. Cao et al. [43] provided a reference for assessing rock burst risk and determining potential rock burst risk areas in the Xuzhuang Coal Mine. Feng et al. [6] established a warning formula to provide some advance warning of rock burst based on the in situ microseismicity and rock burst case studies in tunnels. Xu et al. [35] found the concentration of microseismic events can be used to predict the strainburst location in deep tunnels after analyzing the spatiotemporal evolution of microseismic activity. Dou et al. [44] introduced the R-value scoring method to determine the weights of bursting strain energy, time-space-magnitude independent information, and time-space-magnitude compound information for rock burst warning in Hujiahe Coal Mine. Ma et al. [45] concluded that the geological structure plays a crucial role in the rock burst prediction of deep tunnels at Jinping II Hydropower Station. Additionally, some mathematical modeling approaches and some learning algorithms are used to predict rock burst $[42,46]$. In view of the above work, risk assessment and forecasting studies for rock burst have gained some meaningful results, especially the rock burst risk assessment studies for tunnel and hydraulic engineering.

Simple project layout and long liners are the main features of traffic engineering and hydraulic engineering. Considering the production capacity requirement, multiple stopes at different levels need to be mined at the same time, which leads to the coexistence of numerous goafs in a metal mine. In such conditions, it is difficult for engineers to collect useful information during the rock burst development process. To some degree, it also increases the difficulty of providing early rock burst warning. To date, the rock burst risk assessment method used in metal mines is far from perfect. Considering the differences between the metal mines and the tunnels, such as nonlinearity, simultaneous mining in multimiddle section and multiple stopes and complex layout of shaft and roadway, a specific rock burst risk assessment method is attempted in a metal mine. The site chosen for this study is a deep mining area in the Ashele Copper Mine, Xinjiang Province, China, where the rock bursts are considerable threats to the workers and equipment. The spatiotemporal evolution law of microseismicity is summarized based on the microseismic monitoring system. Then, a model is established to provide the spatialtemporal risk assessment of rock burst. It may provide a reference for determining potential rock burst areas.

\section{Rock Burst Risk Assessment Method}

Microfractures generate in some areas where the stress is concentrated during the mining process [47]. Before the occurrence of a rock burst, microseismicity may increase accompanied with the development of microfracture. A microseismic monitoring system collects seismic waves released by the microfracture using microseismic sensors which are arranged around the target area. Then, the time, location, and parameters of the seismic source can be obtained based on the waves [48]. In general, there are some precursory characteristics of most rock burst in a metal mine. The microseismic method is used to identify the precursory characteristics to provide rock burst risk assessment and management. According to the literature, few rock bursts have no precursory characteristics [6]. Subsequently, all the rock bursts involved in this paper have microseismic precursory characteristics.

\subsection{Determination of Risk Assessment Area and Unit.} Multistope mining at different levels and a complex distribution of long drifts are the main features of a metal mine, making it difficult for rock burst risk assessment and management to cover all areas. The deep stope mining, especially with large scale blasts, would inevitably cause stress concentration in some areas [49]. Combined with strong blasting disturbance, the microseismicity and rock burst risk would be more serious. Considering this, the potential rock burst areas should focus on the area where the distribution of microseismic events is concentrated. However, there is no need for the miners and equipment to enter all the drifts. For example, people only worked in the drift without entering the goaf when a sublevel and long-hole open stoping mining method was adopted. Therefore, the surrounding rock stability of the drift, used as a walkway for miners and equipment, is the main focus of the rock burst assessment and management. After collecting a large number of rock burst cases and matched microseismicity, we use statistical analysis to fix the dimensions of risk assessment unit. 
2.2. Selection of the Microseismic Indicator. According to the literature review, a number of the microseismic parameters, such as cumulative microseismic events, event rate, cumulative energy, energy rate, cumulative apparent volume, apparent volume rate, stress drop, energy index, $b$ value, Schmidt number, and some other parameters, can reflect the microfracture activity and the pregnant process of the rock burst. These parameters can be used as risk assessment indicators individually and can also be used in combination to avoid the randomness of a single parameter [38]. Generally, the selection of the microseismic parameters for rock burst risk assessment mainly relies on empirical analogy. In this paper, the rock burst intensity and the microseismic parameters of the corresponding risk assessment unit are investigated based on the previous studies. And then the correlation analysis of the rock burst intensity and the microseismic parameters are carried out. There will be a significant correlation between the rock burst intensity and a microseismic parameter if their correlation coefficient is big enough. In that case, the microseismic parameter would be used as an indicator of the rock burst risk assessment. On the contrary, it would increase the complexity of the risk assessment model and reduce the risk assessment accuracy. Besides, the indicators used for risk assessment of rock burst should be obtained easily.

According to field destroy situation, rock burst can be classified into intense rock burst, slight rock burst, and none. The main factors considered in the classification are the distance of the flying rock, as well as the depth and volume of the pit, which can be easily obtained. Using the classification criteria, we can collect a database of rock burst cases, which contains intensity and the microseismic parameters of corresponding risk assessment units.

\subsection{Probability Distribution Function of Rock Burst of Dif-} ferent Intensities for Each Indicator. It is well known that microseismic indicators reflect a large amount of information on the rock burst development process from different aspects. For each microseismic indicator, there is a relationship between microseismicity and the probability of different rock burst intensities. Generally, the probability distribution function of rock burst of different intensities is established by fitting analysis based on a large number of cases. Here, a linear function is temporarily used to simplify the description of the probability distribution of rock burst due to a lack of cases. We use the average indicator values of rock burst of different intensities as the eigenvalues to conduct the rock burst early risk assessment. The eigenvalue is the central value of the monitored microseismicity for one rock burst intensity. In other words, the probability of one rock burst intensity is $100 \%$ when the monitored microseismicity equals the eigenvalue, and the probability is 0 when the monitored microseismicity equals the eigenvalue of an adjacent rock burst intensity. With the increase of deviation between the monitored microseismicity and an eigenvalue, the probability of a corresponding rock burst intensity decreases. If the monitored microseismicity is smaller than the lowest eigenvalue, the rock burst of lowest intensity is likely to occur. Similarly, the probability of an intense rock burst reaches $100 \%$ when the monitored microseismicity is bigger than the highest eigenvalue.

2.4. Rock Burst Risk Assessment Formula. As mentioned above, the occurrence of rock burst should be attributed to all the microseismic indicators. Therefore, it should be noted that the rock burst risk assessment should take into account the microseismic indicators according to the correlation analysis. The formula which involves multiple indicators is shown as follows:

$$
P_{i}=\sum_{j=1}^{n} c_{j} P_{j i},
$$

where $i$ represents rock burst intensity, such as intense, slight, and none, corresponding to 3,2 , and $1, j$ is microseismic indicator, and $P_{j i}$ is the probability of $i$ th intensity of microseismic indicator $j$ [6].

It is feasible to calculate the weight coefficients of the microseismic indicators in the formula through PCA. Coefficients represent the contribution of the microseismic indicator to the occurrence of rock burst. Perhaps they are not independent. Using PCA, the information contained in the microseismic indicators can be simplified into $n$ new variables, where $n$ is a value is smaller than the number of microseismic indicators. In this way, the ratio of the original information contained in each new variable can be calculated. Then, the weight coefficients of different microseismic indicators can be obtained according to the coefficient in the expressions of the new variables. After normalization processing, the weight coefficients can be taken as the coefficients of the microseismic indicators in the risk assessment formula.

\section{Background}

The production capability of the Ashele Copper Mine reaches $6000 \mathrm{t}$ per day. The orebody is about 20 to $45 \mathrm{~m}$ thick. Its dip ranges from $70^{\circ}$ to $80^{\circ}$. The mining depth is close to $1000 \mathrm{~m}$. According to the stress measurement results, the maximum principal stress exceeds $40 \mathrm{MPa}$ at the $0 \mathrm{~m}$ level, with a direction that is nearly horizontal. Chalcopyrite is the main mineral, while pyrite and basalt are the surrounding rock. It should be stressed that chalcopyrite and pyrite have a strong rock burst tendency. A large-diameter longhole with the delayed filling open stoping method is dominant in the Ashele Copper Mine. The maximum charge per delay reaches $380 \mathrm{~kg}$, and the maximum charge per blast reaches $5 \mathrm{t}$. At present, rock burst is a serious hazard in the deep mining area.

A SinoSeism microseismic monitoring system with 28 channels is established in the deep mining area. The microseismic monitoring system is composed of four data acquisition units, nineteen unidirectional sensors, and three triaxial sensors, which are installed from $50 \mathrm{~m}$ level to $350 \mathrm{~m}$ level. The frequency response range of the sensors is $10 \sim 2000 \mathrm{~Hz}$. When the sampling frequency is $250 \mathrm{~Hz}$, the signal-to-noise ratio is not less than $120 \mathrm{~dB}$. When the 
sampling frequency is $4000 \mathrm{~Hz}$, the signal-to-noise ratio is not less than $115 \mathrm{~dB}$. Microseismic sensors were installed at the bottom of the hole to avoid the influence of loose zone, which is $6 \mathrm{~m}$ deep. The data acquisition unit is connected to a data exchange center by a communication cable, while the data exchange center is connected to the server on the surface by a fiber optic connection. The locating error of the monitoring system is less than $10 \mathrm{~m}$ according to the blasting test. Many noise signals are mixed with the rock fracture signals. A neural network model was used to eliminate the blasting vibration signals, mechanical vibration signals, and electrical noise signals [50].

\section{Evolution of Microseismic Activity}

Microseismic events mainly gathered from $0 \mathrm{~m}$ level to $150 \mathrm{~m}$ level in the deep mining area of Ashele copper mine, as shown in Figure 1. The size and color represent energy and time of the microseismic events, respectively. Cloud chart distributions of the microseismic event density in the mining area of the Ashele Copper Mine are shown in Figure 2. The events were gathered around the $50 \mathrm{~m}$ level in April, 2017, where the roof of the stopes is at the $0 \mathrm{~m}$ level. Although some new stopes were added at the $300 \mathrm{~m}$ level, there were few changes in the concentrated area and in the clustering degree in September, 2017. The microseismic events appeared in the area ranging from $50 \mathrm{~m}$ level to $150 \mathrm{~m}$ level and rapidly accompanied the fast growth of the mining stopes growing in December, 2017. The microseismic events continued to be concentrated at the $200 \mathrm{~m}$ level in March, 2018. It can be concluded that the mining activities of stopes at the $0 \mathrm{~m}$ level and $150 \mathrm{~m}$ level have a large impact on the distribution of the microseismic events, and mining activities of stopes at the $300 \mathrm{~m}$ level have little impact on it.

The energy index $(E I)$ of a microseismic event is the ratio of the measured radiated microseismic energy generated by the event to the average microseismic energy of all events in the region. It can reflect the stress value indirectly. Cloud chart distributions of $\lg (E I)$ based on microseismic events are shown in Figure 3. The area of concentration for $\lg (E I)$ is apparently different from that of the event density. The areas of concentration of $\lg (E I)$ were distributed from the $50 \mathrm{~m}$ level to the $150 \mathrm{~m}$ level in April, 2017, where the roofs of the stopes at $0 \mathrm{~m}$ level were. As the stopes were mined, the concentration of $\lg (E I)$ in the $100 \mathrm{~m}$ level to $150 \mathrm{~m}$ level range reduced to some extent. Meanwhile, the value of $\lg (E I)$ grew rapidly in the $50 \mathrm{~m}$ level to $100 \mathrm{~m}$ level range, which illustrated that the roof of the stope at the $0 \mathrm{~m}$ level was subject to high damage driven stress. The area of concentration continued to decrease, especially near the stope at the $150 \mathrm{~m}$ level in December, 2017. Only specific concentration region emerged on the roof of the stope at the $0 \mathrm{~m}$ level. The concentration of $\lg (E I)$ demonstrated an invisible increase at the $200 \mathrm{~m}$ level.
According to the concentrated features of microseismic events and the cloud chart distributions of $\lg (E I)$, the high risk area mainly ranges from the $50 \mathrm{~m}$ level to the $250 \mathrm{~m}$ level. The deep stope deformation monitoring data show that the mining disturbed region is approximately $35 \mathrm{~m}$ wide. Microseismic events were concentrated within $30 \mathrm{~m}$ from the stope. Based on the projected layout of the stopes, the sublevel haulage drifts on the footwall and hanging wall from the $0 \mathrm{~m}$ level to the $350 \mathrm{~m}$ level are classified into a group that requires risk assessment work to be covered. The stress reduced area, stress concentration area, and initial stress area are observed around the stope through drift deformation monitoring. In addition, there are many microseismic events in the stress concentration area, where there is less than $30 \mathrm{~m}$ from the goaf. Combining the size of the drift, the spatial risk assessment unit, which takes the drift stalk line as the center, is $30 \mathrm{~m}$ high, $30 \mathrm{~m}$ long, and $30 \mathrm{~m}$ wide.

\section{Risk Assessment of Rock Burst in Ashele Copper Mine}

The rock burst intensity can be divided into three types in the Ashele Copper Mine: intense rock burst (see Figure 4), slight rock burst (see Figure 5), and none rock burst. To consider the temporal evolution process of rock burst, microseismic events rate, microseismic energy rate, and microseismic apparent volume rate use 3 days as the time window, and others use 7 days. The sliding length of the time window is 24 hours. According to the above method, the rock burst with different intensities and the microseismic parameters of the corresponding risk assessment unit are counted. After the correlation analysis between the microseismic parameter and rock burst intensity, six microseismic parameters, such as cumulative event number, cumulative energy, cumulative apparent volume, event rate, energy release rate, and apparent volume rate, are selected to study rock burst risk assessment. The values of the samples can be seen in Figure 6.

The averages of the microseismic indicators for different rock burst intensities are obtained as the eigenvalues. These eigenvalues are the key values for rock burst risk assessment. When the value of a microseismic parameter approaches an eigenvalue of rock burst, the corresponding intensity rock burst is likely to occur. If the value of a microseismic parameter is smaller than the eigenvalue of the lowest level of rock burst, there will be none rock burst. Similarly, the risk of the highest level of rock burst will reach $100 \%$ as the value exceeds the highest eigenvalue. In practice, we used the eigenvalue of the adjacent level of rock burst as the boundary for the corresponding rock burst intensity. When the value of $P_{j i}$ is close to 1 , the $i$ th intensity rock burst will occur most easily, according to the microseismic parameter $j$.

In Table $1, A_{j i}$ represents the eigenvalue of the $i$ th level of rock burst for microseismic indicator $j$. The probability 


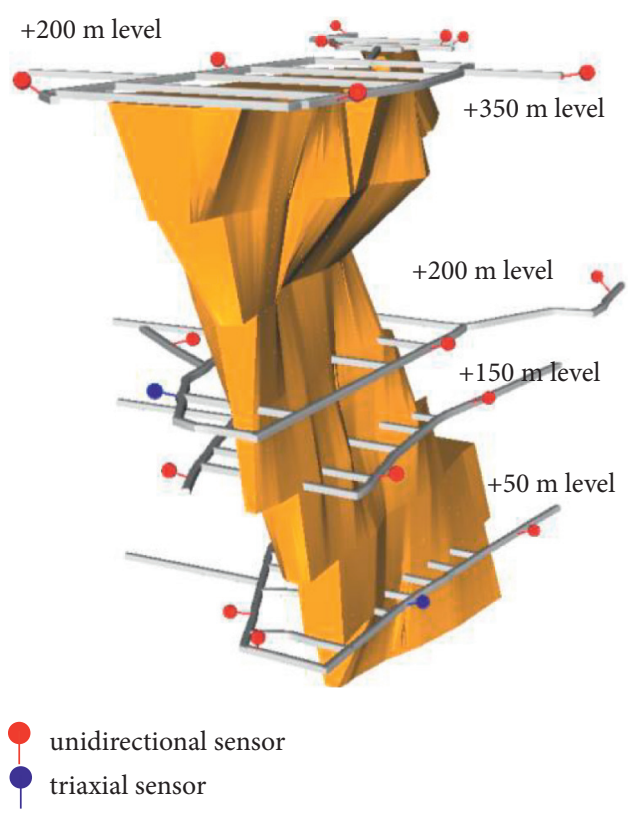

(a)

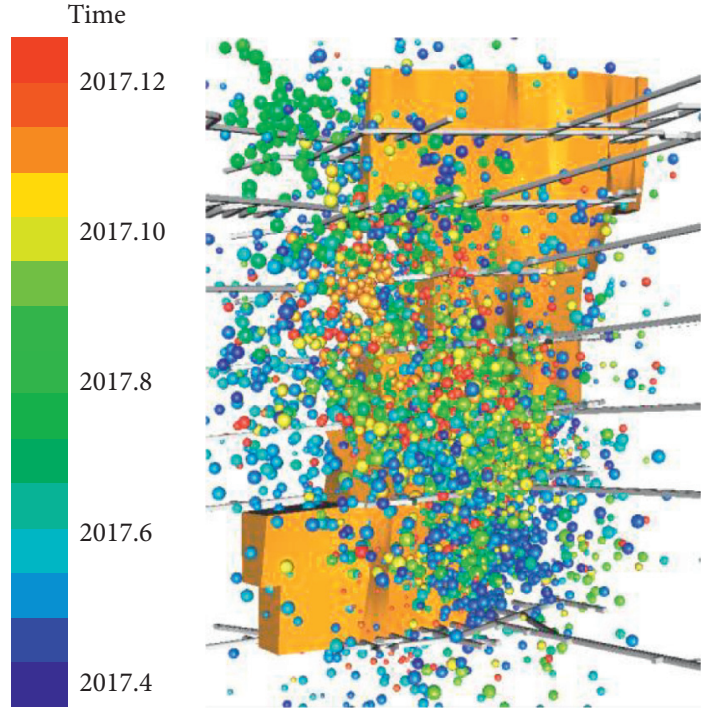

(b)

FIgURe 1: (a) Layout of sensors [50] and (b) spatial distribution of microseismic events in the deep mining area.

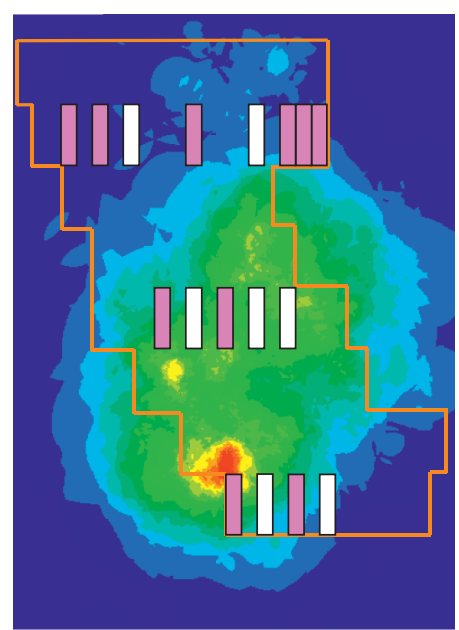

Mining stope ㄱilling stope ○ Ore boundary

(a)

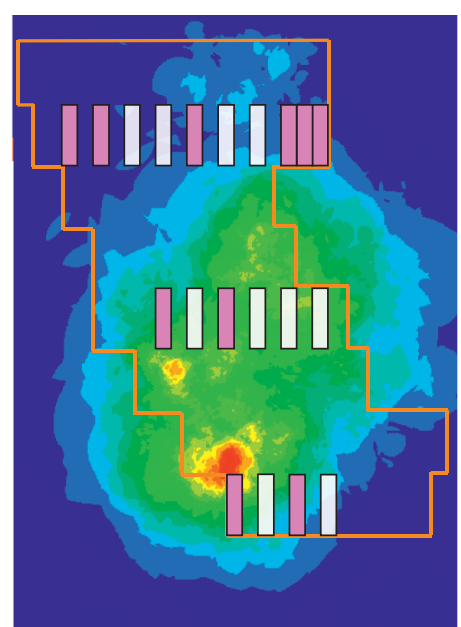

(7) Mining stope

Filling stope

- Ore boundary

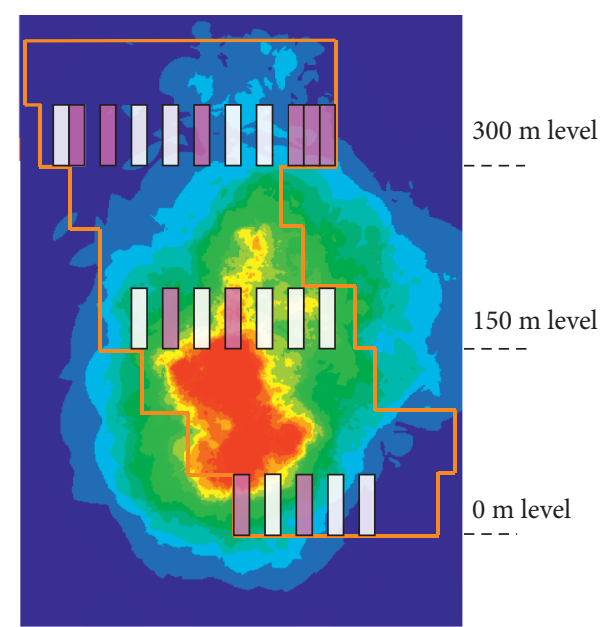

(1) Mining stope

Filling stope

$\square$ Ore boundary

(c)

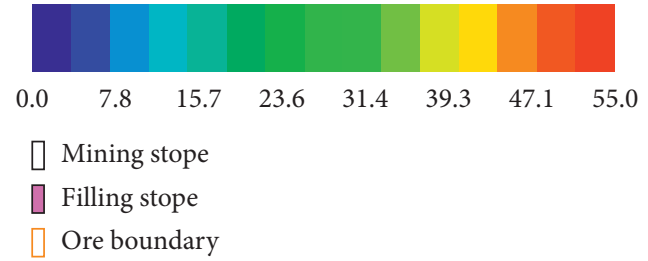

(d)

Figure 2: Cloud chart distributions of the microseismic event density. (a) 2017.6. (b) 2017.9. (c) 2017.12. (d) Legend (per square meter). 


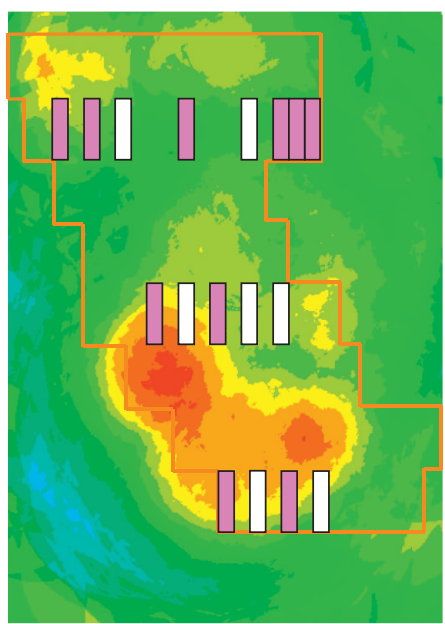

- Mining stope

- Filling stope

○ Ore boundary

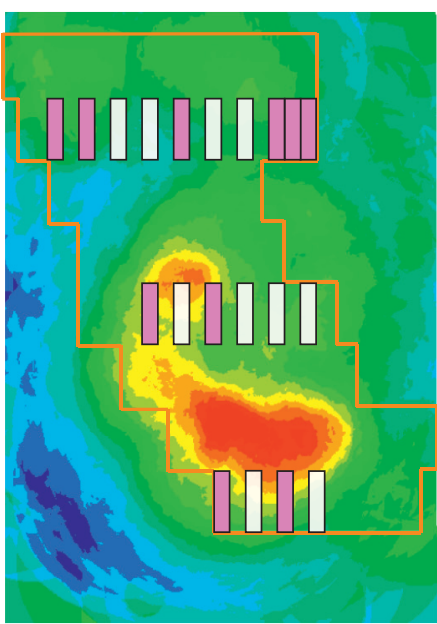

- Mining stope

Filling stope

$\square$ Ore boundary

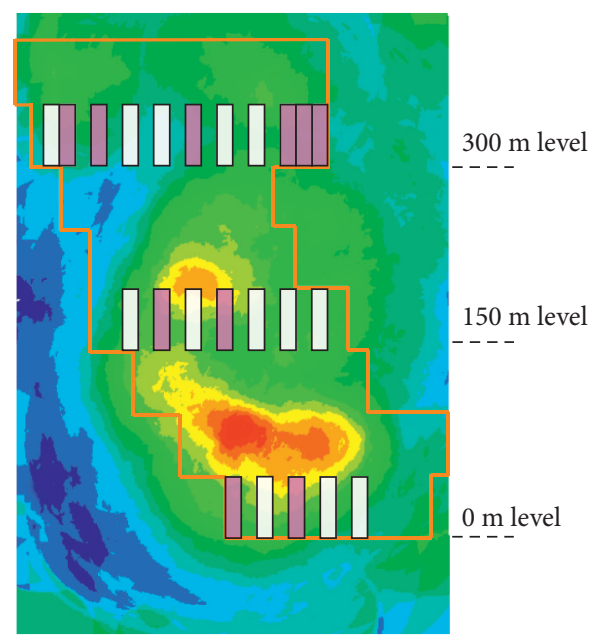

- Mining stope

- Filling stope

] Ore boundary

(a)

(c)

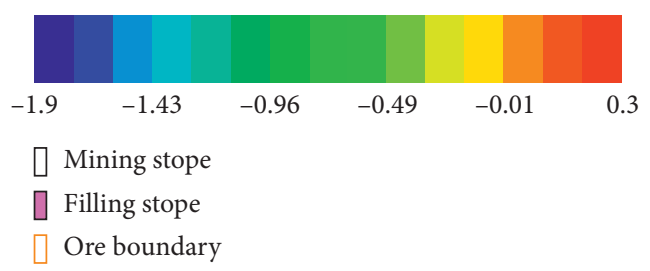

(d)

Figure 3: Cloud chart distributions of $\lg$ (EI). (a) 2017.6. (b) 2017.9. (c) 2017.12. (d) Legend.

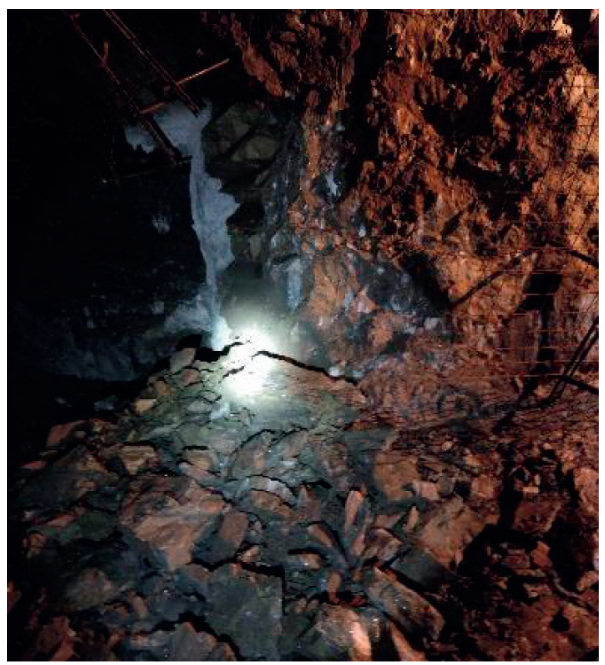

Figure 4: Intense rock burst in Ashele Copper Mine. 


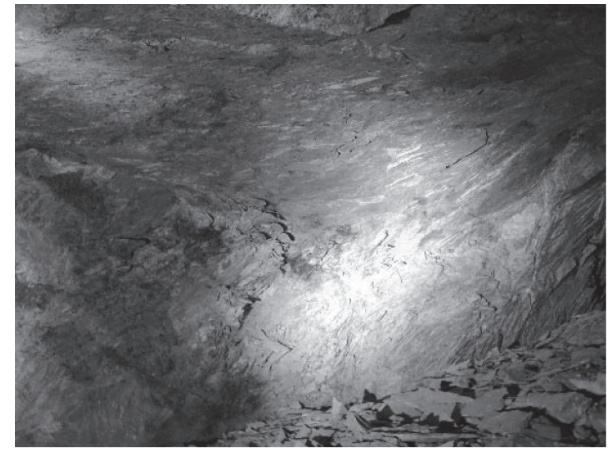

Figure 5: Slight rock burst in Ashele Copper Mine.

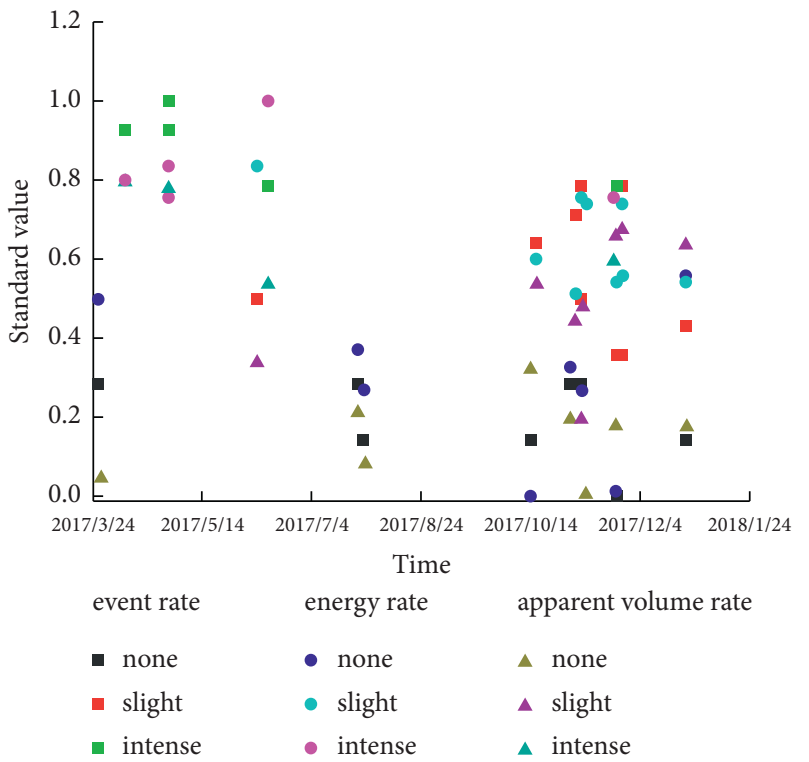

(a)

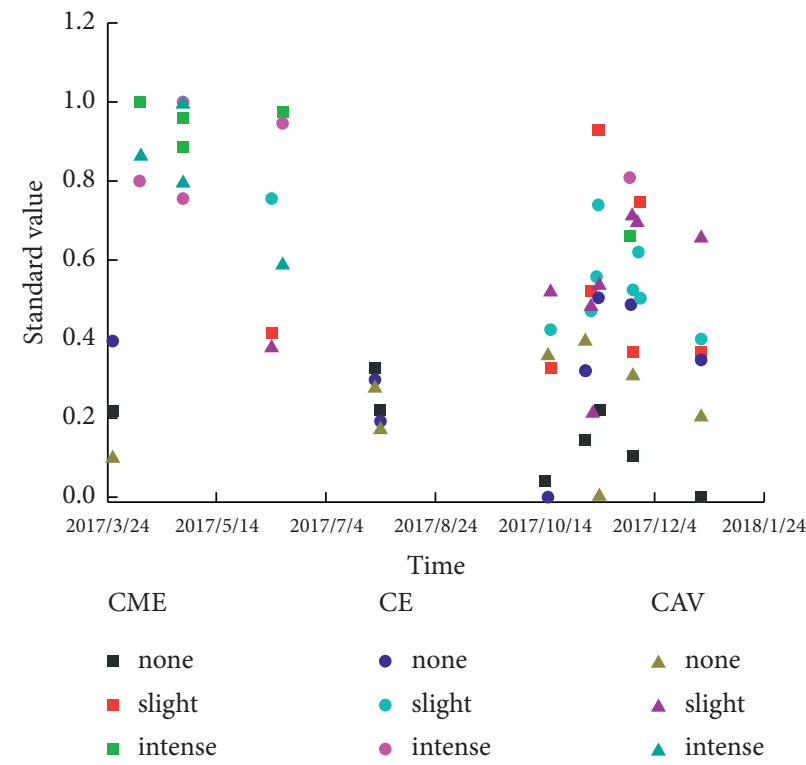

(b)

Figure 6: The whole processed time series of the six indicators. (a) Event rate, energy rate, and apparent volume rate. (b) Cumulative number of event (CME), energy (CE), and apparent volume (CAV).

TABle 1: Eigenvalues of microseismic indicators for rock burst of different intensities.

\begin{tabular}{|c|c|c|c|c|}
\hline No. & Microseismic indicator & $A_{j 1}$ & $A_{j 2}$ & $A_{j 3}$ \\
\hline 1 & Cumulative microseismic events (per week) & 10.375 & 18.889 & 30.200 \\
\hline 2 & Microseismic event rate (per 3 days) & 1.917 & 3.630 & 5.135 \\
\hline 3 & Cumulative energy lgE (J per week) & 4.757 & 5.204 & 5.757 \\
\hline 4 & Energy released rate lgE (J per 3 days) & 3.797 & 4.521 & 4.882 \\
\hline 5 & Cumulative apparent volume $\lg \mathrm{V}\left(\mathrm{m}^{3}\right.$ per week) & 5.522 & 6.822 & 7.810 \\
\hline 6 & Apparent volume rate $\lg \mathrm{V}\left(\mathrm{m}^{3}\right.$ per 3 days $)$ & 4.831 & 6.181 & 7.019 \\
\hline
\end{tabular}


functions for different rock burst intensities when the value of indicator equals $M$ as follows:

$$
\begin{aligned}
& P_{11}= \begin{cases}1, & 0 \leq M \leq A_{j 1}, \\
\frac{A_{j 2}-M}{A_{j 2}-A_{j 1}}, & A_{j 1}<M<A_{j 2}, \\
& 0, A_{j 2} \leq M,\end{cases} \\
& P_{12}= \begin{cases}0, & 0 \leq M \leq A_{j 1}, A_{j 3} \leq M, \\
\frac{M-A_{j 1}}{A_{j 2}-A_{j 1}}, & A_{j 1}<M<A_{j 2}, \\
\frac{A_{j 3}-M}{A_{j 3}-A_{j 2}}, & A_{j 2}<M<A_{j 3},\end{cases} \\
& P_{13}= \begin{cases}0, & 0 \leq M \leq 18.889, \\
\frac{M-A_{j 2}}{A_{j 3}-A_{j 2}}, & 18.889<M<30.200, \\
1, & 30.200 \leq M .\end{cases}
\end{aligned}
$$

The probabilities of different rock burst intensities for cumulative microseismic events are shown in Figure 7(a). The probabilities for other microseismic parameters can be obtained in the same way.

Before using PCA, we carried out the Kaiser-MeyerOlkin (KMO) test to judge the feasibility of PCA for the matrix. As a result, the value of $\mathrm{KMO}$ is 0.756 , which illustrates that PCA can be used to solve the matrix. The total variance of the interpretation is shown in Table 2. Generally, the new principle components of PCA need to contain more than $85 \%$ of the original information. In this paper, there are about $91.28 \%$ of the original information exiting in the first two principle components. So the first two principle components are selected to calculate the ingredient matrix, which are listed in Table 3 . The coefficients of the microseismic parameters list in the new principle components are equal to the ratio of the corresponding ingredient matrix element to the square root of the eigenvalue. Then the two principal component can be expressed as

$$
\begin{aligned}
& X 1=0.431 x_{1}+0.432 x_{2}+0.394 x_{3}+0.384 x_{4}+0.400 x_{5}+0.407 x_{6} \\
& X 2=0.071 x_{1}+0.068 x_{2}+0.458 x_{3}+0.478 x_{4}-0.543 x_{5}-0.508 x_{6} .
\end{aligned}
$$

The proportional contribution of the accumulated microseismic events is calculated as follows:

$$
c_{1}=\frac{(0.431 \times 78.584+0.071 \times 12.695)}{78.584+12.695}=0.381 \text {. }
$$

The microseismic indicator weight model is obtained as follows:

$$
\begin{aligned}
Y= & 0.381 x_{1}+0.381 x_{2}+0.403 x_{3}+0.397 x_{4}+0.269 x_{5} \\
& +0.279 x_{6} .
\end{aligned}
$$

The weight coefficients are determined after normalized processing.

$$
\begin{aligned}
Y & =\left\{c_{1}, c_{2}, c_{3}, c_{4}, c_{5}, c_{6}\right\} \\
& =\{0.180,0.181,0.191,0.188,0.127,0.132\} .
\end{aligned}
$$

Therefore, the rock burst probability formula for different intensities is as follows:

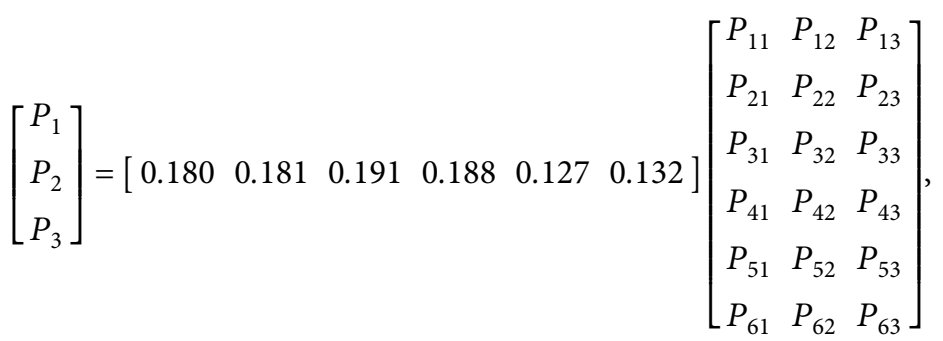




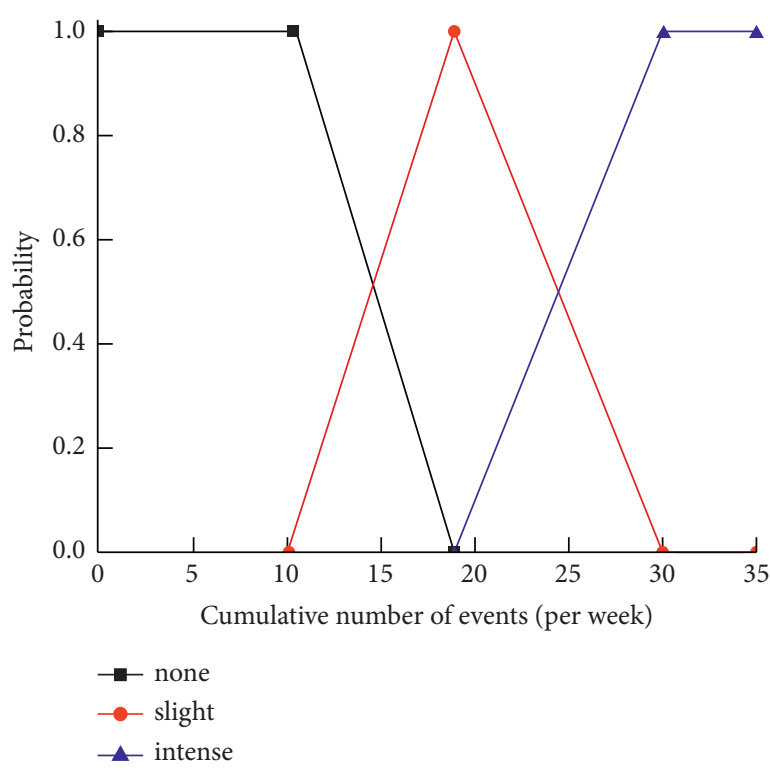

(a)

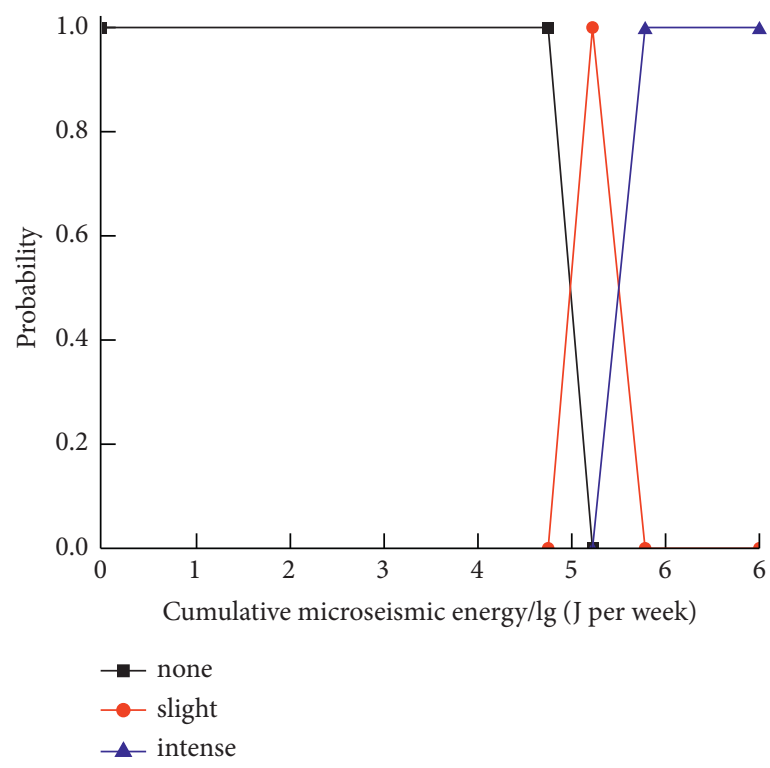

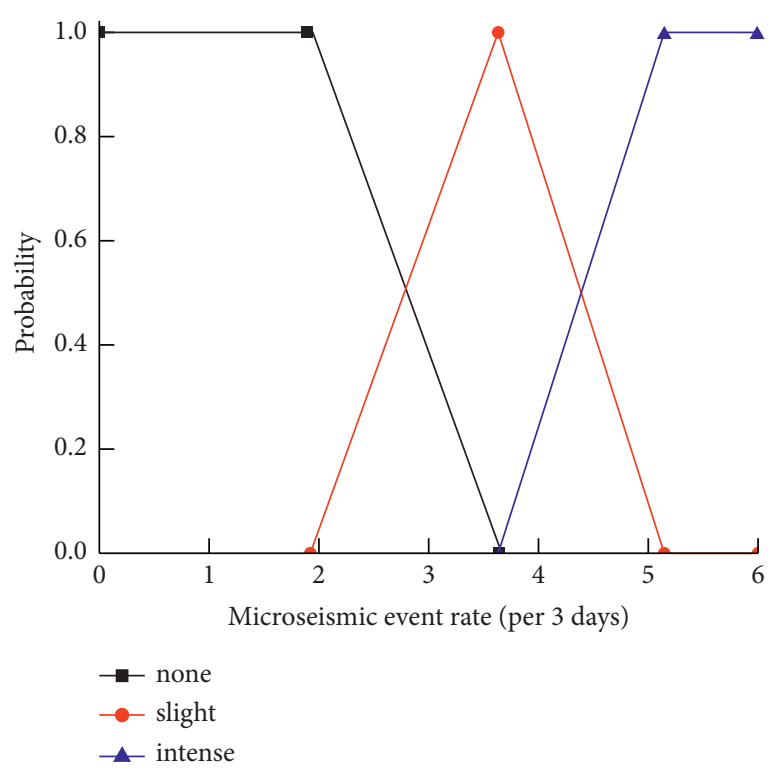

(b)

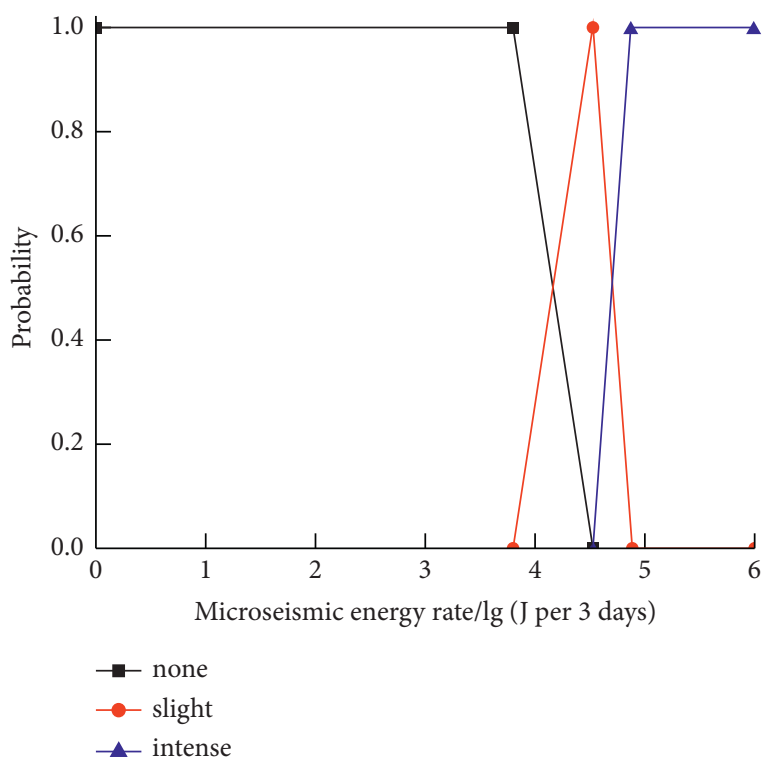

(d)

FIgURE 7: Continued. 


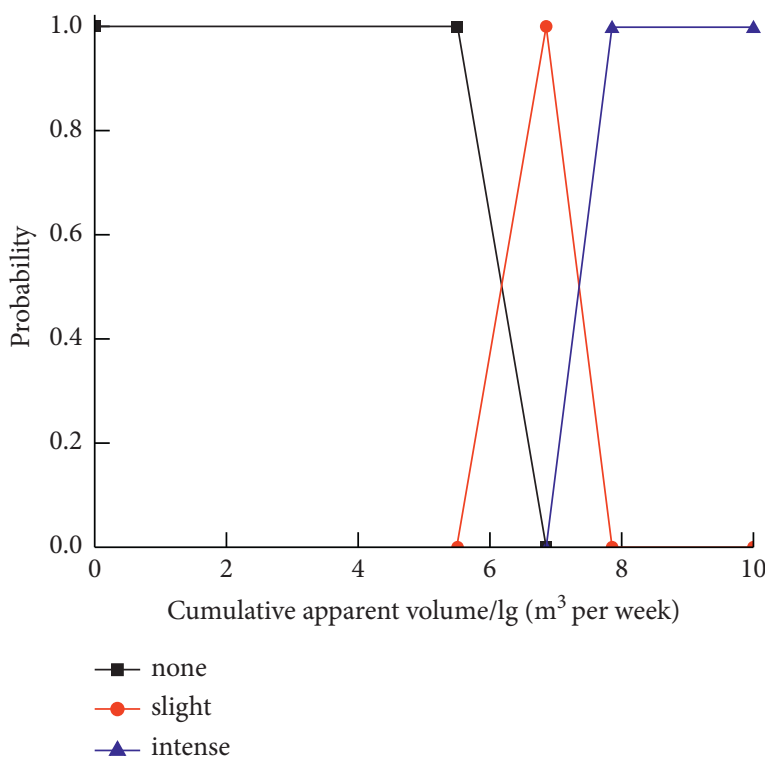

(e)

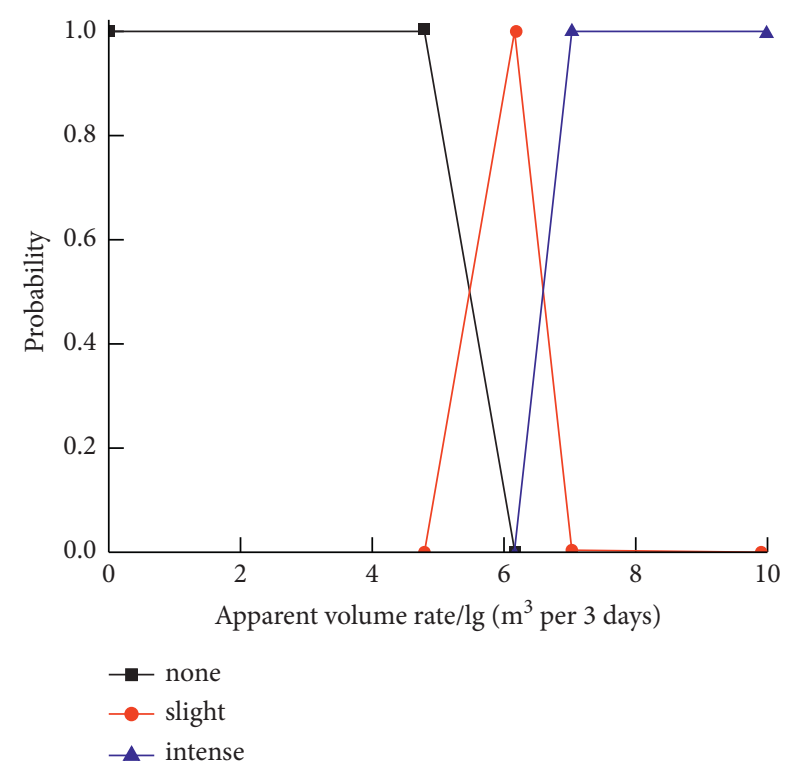

(f)

Figure 7: Probability of rock burst of different intensities for each microseismic indicator. (a) Cumulative number of events. (b) Microseismic event rate. (c) Cumulative microseismic energy. (d) Microseismic energy rate. (e) Cumulative apparent volume. (f) Apparent volume rate.

TABLE 2: Total variance of the interpretation.

\begin{tabular}{lccc}
\hline Component & \multicolumn{2}{c}{$\begin{array}{c}\text { Initial eigenvalues } \\
\text { Proportion of variance \% }\end{array}$} \\
\hline 1 & Total & 78.584 & 78.584 \\
2 & 4.715 & 12.695 & 91.279 \\
3 & 0.762 & 4.517 & 95.796 \\
4 & 0.271 & 3.055 & 98.851 \\
5 & 0.183 & 0.977 & 99.828 \\
6 & 0.059 & 0.172 & 100.000 \\
\hline
\end{tabular}

TABLE 3: Ingredient matrix for the microseismic indicators.

\begin{tabular}{lcr}
\hline Variable & \multicolumn{1}{c}{ Ingredient } \\
\hline VAR00001 & 1 & 0.062 \\
VAR00002 & 0.936 & 0.059 \\
VAR00003 & 0.938 & 0.399 \\
VAR00004 & 0.855 & 0.417 \\
VAR00005 & 0.833 & -0.474 \\
VAR00006 & 0.868 & -0.443 \\
\hline
\end{tabular}

where $P_{1}, P_{2}$, and $P_{3}$ represent none rock burst, slight rock burst, and intense rock burst, respectively.

A risk assessment alarm triggered in the north of the footwall haulage drift on 26th March, 2018. The monitored values of the microseismic parameters are shown in Table 4.

The rock burst probabilities for different intensities are calculated as follows:

$$
\left[\begin{array}{l}
P_{1} \\
P_{2} \\
P_{3}
\end{array}\right]=\left[\begin{array}{c}
0 \\
0.334 \\
0.666
\end{array}\right] .
$$

As a result, the probabilities of the intense rock burst, slight rock burst, and none rock burst in the region are $66.6 \%, 33.4 \%$, and 0 , respectively. 
TABle 4: Microseismic parameters in a spatial waning unit.

\begin{tabular}{lccccc}
\hline $\begin{array}{l}\text { Cumulative microseismic } \\
\text { events/per week }\end{array}$ & $\begin{array}{c}\text { Microseismic event } \\
\text { rate/per 3 days }\end{array}$ & $\begin{array}{c}\text { Cumulative } \\
\text { energy/lg (J per week) }\end{array}$ & $\begin{array}{c}\text { Microseismic energy } \\
\text { rate/lg } \\
(\mathrm{J} \text { per 3 days })\end{array}$ & $\begin{array}{c}\text { Cumulative apparent } \\
\text { volume/lg } \\
\left(\mathrm{m}^{3} \text { per week }\right)\end{array}$ & $\begin{array}{c}\text { Apparent } \\
\text { volume rate/lg } \\
\left(\mathrm{m}^{3} \text { per 3 days }\right)\end{array}$ \\
\hline 27 & 5.67 & 5.42 & 4.57 & 7.85 & 7.27 \\
\hline
\end{tabular}

The results show that the probability of the intense rock burst in the region is $66.6 \%$ and $33.4 \%$ for slight rock burst and $0 \%$ for none rock burst. Finally, an intense rock burst occurred in the region on the next day, with a large amount of noise and rock ejection. The result is shown in Figure 8.

The method can predict about $70 \%$ of rock burst after two years of application. In practice, there was one rock burst accompanied by no apparent changes in the microseismic indicators, resulting in no warning before its occurrence. In addition, it was difficult to find obvious changes in the microseismic indicators for some rock burst during the establishment of the rock burst database. As a result, we did not pay attention to this type rock burst in this study.

\section{Discussion}

In the rock burst risk assessment formula, the coefficients of microseismic event rate, cumulative microseismic events, energy release rate, cumulative energy, apparent volume rate, and cumulative apparent volume are 0.180 , $0181,0.191,0.188,0.127$, and 0.132 , respectively, which show the different contributions to the rock burst probability. Obviously, the energy release rate and cumulative energy offer the greatest impact to rock burst from among the microseismic indicators involved in the formula. According to Wang and Park [51], the energy accumulation during the mining process is one of two main impact factors for rock burst. Additionally, Wiles [52] indicated the local energy release rate can be used to predict rock burst because of their strong correlation. However, according to Zhou et al. [36], few approaches based on the single energy index have been found to be particularly successful. The coefficients in the rock burst risk assessment formula may explain the above relationship. The microseismic event rate and cumulative microseismic events are almost equally important, along with the energy release rate and cumulative energy. This is why multiple parameters can be used in combination to avoid the shortcomings of a single parameter.

The application of the proposed method in the Ashele Copper Mine has proven that it is feasible to perform rock burst risk assessment through a combination of a simplified probability distribution function and PCA. With deep mine exploitation, more rock burst cases will be collected, and the eigenvalues of rock burst of different intensities will increase or decrease slightly. By then, a fitting function can be used to replace the liner function to describe the probability of different intensity rock burst. In that case, the successful warning rate would apparently increase. Furthermore, the information contained in the rock burst database should be detailed as much as possible for a future rainy day.

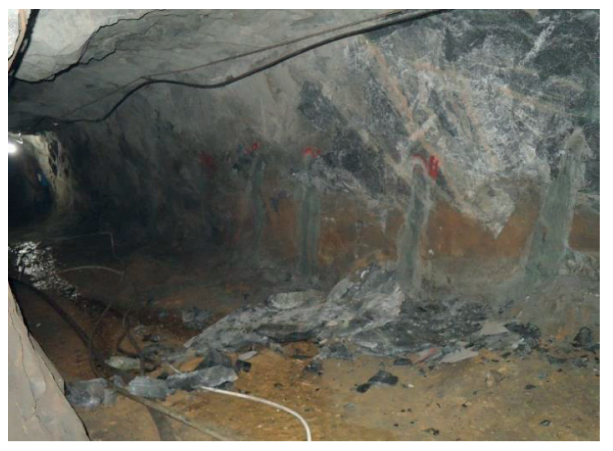

Figure 8: Intense rock burst at the $150 \mathrm{~m}$ level.

\section{Conclusion}

The study of rock burst risk assessment and management is important for miners to prevent rock burst. This paper presents a methodology combining a simplified probability function and PCA to allow for early risk assessment of rock burst of different intensities. The microseismic event rate, cumulative microseismic events, microseismic energy rate, cumulative microseismic energy, apparent volume rate, and cumulative apparent volume are taken as microseismic indicators. A liner function was used to describe a simplified probability distribution for rock burst of different intensities for each indicator. Then, the coefficients of the microseismic indicators were calculated by PCA to establish the rock burst risk assessment formula. According to the Ashele Copper Mine rock burst database, the energy release rate, and cumulative energy have the highest contribution to the rock burst probability, followed by the microseismic event rate and cumulative microseismic events, with the apparent volume rate and the cumulative apparent volume last. The application of rock burst risk assessment in the Ashele Copper Mine illustrates that the proposed method is an effective tool for predicting rock burst in metal mines.

\section{Data Availability}

The datasets used in the present study are available from the corresponding author upon reasonable request.

\section{Conflicts of Interest}

The authors declare that they have no conflicts of interest.

\section{Acknowledgments}

This work was financially supported by project 2016YFC0801605 of the National Key Research and Development Plan of China, projects 51704056 and 51974059 
of the National Natural Science Foundation of China, and projects N182608003 and N2001001 of the Fundamental Research Funds for the Central University of China.

\section{References}

[1] A. M. Milev and S. M. Spottiswoode, "Integrated seismicity around deep-level stopes in South Africa," International Journal of Rock Mechanics and Mining Sciences, vol. 34, no. 34, pp. 199-e1, 1997.

[2] C. Fan, S. Li, D. Elsworth, J. Han, and Z. Yang, "Experimental investigation on dynamic strength and energy dissipation characteristics of gas outburst-prone coal," Energy Science \& Engineering, vol. 8, no. 4, pp. 1015-1028, 2020.

[3] C. Fan, L. Yang, G. Wang, Q. Huang, X. Fu, and H. Wen, "Investigation on coal skeleton deformation in $\mathrm{CO} 2$ injection enhanced $\mathrm{CH} 4$ drainage from underground coal seam," Frontiers of Earth Science, vol. 9, Article ID 766011, 2021.

[4] X. T. Feng, S. Webber, and M. U. Ozbay, "Neural network assessment of rockburst risks for deep gold mines in South Africa," Transactions of Nonferrous Metals Society of China, vol. 8, no. 2, pp. 335-341, 1998.

[5] M. Cai, "Prediction and prevention of rockburst in metal mines - a case study of Sanshandao gold mine," Journal of Rock Mechanics and Geotechnical Engineering, vol. 8, no. 2, pp. 204-211, 2016.

[6] G.-L. Feng, X.-T. Feng, B.-r. Chen, Y.-X. Xiao, and Y. Yu, “A microseismic method for dynamic warning of rockburst development processes in tunnels," Rock Mechanics and Rock Engineering, vol. 48, no. 5, pp. 2061-2076, 2015.

[7] B.-R. Chen, X.-T. Feng, Q.-P. Li, R.-Z. Luo, and S. Li, "Rock burst intensity classification based on the radiated energy with damage intensity at Jinping II hydropower station, China," Rock Mechanics and Rock Engineering, vol. 48, no. 1, pp. 289-303, 2013.

[8] J. Wang, J. Yang, F. Wu, T. Hu, and S. A. Faisal, "Analysis of fracture mechanism for surrounding rock hole based on water-filled blasting," International Journal of Coal Science \& Technology, vol. 7, no. 4, pp. 704-713, 2020.

[9] N. Barton, R. Lien, and J. Lunde, "Engineering classification of rock masses for the design of tunnel support," Rock Mechanics Felsmechanik Mcanique des Roches, vol. 6, no. 4, pp. 189-236, 1974.

[10] S. Li, X.-T. Feng, Z. Li, B. Chen, C. Zhang, and H. Zhou, "In situ monitoring of rockburst nucleation and evolution in the deeply buried tunnels of Jinping II hydropower station," Engineering Geology, vol. 137-138, pp. 85-96, 2012.

[11] J. Zhou, X.-z. Shi, R.-d. Huang, X.-y. Qiu, and C. Chen, "Feasibility of stochastic gradient boosting approach for predicting rockburst damage in burst-prone mines," Transactions of Nonferrous Metals Society of China, vol. 26, no. 7, pp. 1938-1945, 2016.

[12] G. Van Aswegen, "Routine seismic hazard assessment in some South African mines," in Proceedings of the Sixth International Symposium on Rockburst and Seismicity in Mines, pp. 437-444, Australian Centre for Geomechanics, Nedlands, 2005.

[13] P. K. Kaiser and M. Cai, "Design of rock support system under rockburst condition," Journal of Rock Mechanics and Geotechnical Engineering, vol. 4, no. 3, pp. 215-227, 2012.

[14] R. J. Durrheim, A. Haile, M. K. C. Roberts, J. K. Schweitzer, S. M. Spottiswoode, and J. W. Klokow, "Violent failure of a remnant in a deep South African gold mine," Tectonophysics, vol. 289, no. 1-3, pp. 105-116, 1998.
[15] Z. Liu, J. Shao, W. Xu, and Y. Meng, "Prediction of rock burst classification using the technique of cloud models with attribution weight," Natural Hazards, vol. 68, no. 2, pp. 549-568, 2013.

[16] R. Frith, G. Reed, and A. Jones, "A causation mechanism for coal bursts during roadway development based on the major horizontal stress in coal: very specific structural geology causing a localised loss of effective coal confinement and Newton's second law," International Journal of Mining Science and Technology, vol. 30, no. 1, pp. 39-47, 2020.

[17] M. Cai and E. T. Brown, "Challenges in the mining and utilization of deep mineral resources," Engineering, vol. 3, no. 4, pp. 432-433, 2017.

[18] F. T. Suorineni, B. Hebblewhite, and S. Saydam, "Geomechanics challenges of contemporary deep mining: a suggested model for increasing future mining safety and productivity," Journal of the South African Institute of Mining and Metallurgy, vol. 114, no. 12, pp. 1023-1032, 2014.

[19] G.-F. Liu, X.-T. Feng, G.-L. Feng, B.-R. Chen, D.-F. Chen, and S.-Q. Duan, "A method for dynamic risk assessment and management of rockbursts in drill and blast tunnels," Rock Mechanics and Rock Engineering, vol. 49, no. 8, pp. 3257-3279, 2016.

[20] X. Liu, Z. Liang, Y. Zhang, P. Liang, and B. Tian, "Experimental study on the monitoring of rockburst in tunnels under dry and saturated conditions using AE and infrared monitoring," Tunnelling and Underground Space Technology, vol. 82, pp. 517-528, 2018.

[21] W. Cai, L. Dou, S. Gong, Z. Li, and S. Yuan, "Quantitative analysis of seismic velocity tomography in rock burst hazard assessment," Natural Hazards, vol. 75, no. 3, pp. 2453-2465, 2015.

[22] L. Dou, T. Chen, S. Gong, H. He, and S. Zhang, "Rockburst hazard determination by using computed tomography technology in deep workface," Safety Science, vol. 50, no. 4, pp. 736-740, 2012.

[23] C. L. Wang, A. X. Wu, H. Lu, T. C. Bao, and X. H. Liu, "Predicting rockburst tendency based on fuzzy matter-element model," International Journal of Rock Mechanics and Mining Sciences, vol. 75, pp. 224-232, 2015.

[24] X.-T. Feng, Y. Yu, G.-L. Feng, Y.-X. Xiao, B.-R. Chen, and Q. Jiang, "Fractal behaviour of the microseismic energy associated with immediate rockbursts in deep, hard rock tunnels," Tunnelling and Underground Space Technology, vol. 51, pp. 98-107, 2016.

[25] M. He, H. Xia, X. Jia, W. Gong, F. Zhao, and K. Liang, "Studies on classification, criteria and control of rockbursts," Journal of Rock Mechanics and Geotechnical Engineering, vol. 4, no. 2, pp. 97-114, 2012.

[26] L. Dou, K. Yang, and X. Chi, "Fracture behavior and acoustic emission characteristics of sandstone samples with inclined precracks," International Journal of Coal Science \& Technology, vol. 8, no. 1, pp. 77-87, 2021.

[27] S. Afraei, K. Shahriar, and S. H. Madani, "Statistical assessment of rock burst potential and contributions of considered predictor variables in the task," Tunnelling and Underground Space Technology, vol. 72, pp. 250-271, 2018.

[28] X. T. Feng, C. Q. Zhang, S. J. Li, S. L. Qiu, and S. Y. Wu, Mechanism, Warning and Dynamic Control of Rockburst Development Process, Science Press, Beijing, China, 2013.

[29] X. Feng, B. Chen, S. Li et al., "Studies on the evolution process of rockbursts in deep tunnels," Journal of Rock Mechanics and Geotechnical Engineering, vol. 4, no. 4, pp. 289-295, 2012. 
[30] F. Gong, Y. Wang, Z. Wang, J. Pan, and S. Luo, "A new criterion of coal burst proneness based on the residual elastic energy index," International Journal of Mining Science and Technology, vol. 31, no. 4, pp. 553-563, 2021.

[31] V. A. Mansurov, "Prediction of rockbursts by analysis of induced seismicity data," International Journal of Rock Mechanics and Mining Sciences, vol. 38, no. 6, pp. 893-901, 2001.

[32] R. J. Durrheim, A. Cichowicz, R. Ebrahim-Trollope et al., "Guidelines, standards and best practice for seismic hazard assessment and rockburst risk management in South African mines," in Proceeding of the 4th International Seminar on Deep and High Stress Mining, pp. 249-261, Perth, Australia, 2007.

[33] A. Lurka, "Location of high seismic activity zones and seismic hazard assessment in Zabrze Bielszowice coal mine using passive tomography," Journal of China University of Mining and Technology, vol. 18, no. 2, pp. 177-181, 2008.

[34] C. J. Fan, S. Li, M. K. Luo, W. Z. Du, and Z. H. Yang, "Coal and gas outburst dynamic system," International Journal of Mining Science and Technology, vol. 27, no. 01, pp. 49-55, 2017.

[35] N. W. Xu, T. B. Li, F. Dai, R. Zhang, C. A. Tang, and L. X. Tang, "Microseismic monitoring of strainburst activities in deep tunnels at the Jinping II hydropower station, China," Rock Mechanics and Rock Engineering, vol. 49, no. 3, pp. 981-1000, 2016.

[36] T. H. Ma, C. A. Tang, L. X. Tang, W. D. Zhang, and L. Wang, "Rockburst characteristics and microseismic monitoring of deep-buried tunnels for Jinping II Hydropower Station," Tunnelling and Underground Space Technology, vol. 49, pp. 345-368, 2015.

[37] J. Zhou, X. Li, and H. S. Mitri, "Evaluation method of rockburst: state-of-the-art literature review," Tunnelling and Underground Space Technology, vol. 81, pp. 632-659, 2018.

[38] R. F. Poplawski, "Seismic parameters and rockburst hazard at Mt Charlotte mine," International Journal of Rock Mechanics and Mining Sciences, vol. 34, no. 8, pp. 1213-1228, 1997.

[39] J. M. Alcott, P. K. Kaiser, and B. P. Simser, "Use of microseismic source parameters for rockburst hazard assessment," in Seismicity Caused by Mines, Fluid Injections, Reservoirs, and Oil Extraction, pp. 41-65, Birkhäuser, Basel, Switzerland, 1998.

[40] L.-Z. Tang and K. W. Xia, "Seismological method for prediction of areal rockbursts in deep mine with seismic source mechanism and unstable failure theory," Journal of Central South University of Technology, vol. 17, no. 5, pp. 947-953, 2010.

[41] C. A. Tang, J. Wang, and J. Zhang, "Preliminary engineering application of microseismic monitoring technique to rockburst prediction in tunneling of Jinping II project," Journal of Rock Mechanics and Geotechnical Engineering, vol. 2, no. 3, pp. 193-208, 2010.

[42] J. Zhou, X. Li, and X. Shi, "Long-term prediction model of rockburst in underground openings using heuristic algorithms and support vector machines," Safety Science, vol. 50, no. 4, pp. 629-644, 2012.

[43] A.-Y. Cao, L.-M. Dou, C.-B. Wang, X.-X. Yao, J.-Y. Dong, and $\mathrm{Y}$. Gu, "Microseismic precursory characteristics of rock burst hazard in mining areas near a large residual coal pillar: a case study from Xuzhuang coal mine, Xuzhou, China," Rock Mechanics and Rock Engineering, vol. 49, no. 11, pp. 4407-4422, 2016.

[44] L. Dou, W. Cai, A. Cao, and W. Guo, "Comprehensive early warning of rock burst utilizing microseismic multi-parameter indices," International Journal of Mining Science and Technology, vol. 28, no. 5, pp. 767-774, 2018.

[45] C. C. Ma, T. B. Li, H. Zhang, and J. F. Wang, "An evaluation and early warning method for rockburst based on EMS microseismic source parameters," Rock and Soil Mechanics, vol. 39, no. 2, pp. 765-774, 2018.

[46] N. Li and R. Jimenez, "A logistic regression classifier for longterm probabilistic prediction of rock burst hazard," Natural Hazards, vol. 90, no. 1, pp. 197-215, 2018.

[47] M. Cai, P. K. Kaiser, Y. Tasaka, T. Maejima, H. Morioka, and M. Minami, "Generalized crack initiation and crack damage stress thresholds of brittle rock masses near underground excavations," International Journal of Rock Mechanics and Mining Sciences, vol. 41, no. 5, pp. 833-847, 2004.

[48] S.-D. Xu, Y.-H. Li, and J.-P. Liu, "Detection of cracking and damage mechanisms in brittle granites by moment tensor analysis of acoustic emission signals," Acoustical Physics, vol. 63, no. 3, pp. 359-367, 2017.

[49] I. Vennes, H. Mitri, D. R. Chinnasane, and M. Yao, "Largescale destress blasting for seismicity control in hard rock mines: a case study," International Journal of Mining Science and Technology, vol. 30, no. 2, pp. 141-149, 2020.

[50] S. Xu, C. Zhang, Z. Chen, Y. Li, and J. Liu, "Accurate identification of microseismic waveforms based on an improved neural network model," Journal of Applied Geophysics, vol. 190, Article ID 104343, 2021.

[51] J.-A. Wang and H. D. Park, "Comprehensive prediction of rockburst based on analysis of strain energy in rocks," Tunnelling and Underground Space Technology, vol. 16, no. 1, pp. 49-57, 2001.

[52] T. D. Wiles, "Loading system stiffness-a parameter to evaluate rockburst potential," in Proceedings of the First International Seminar on Deep and High Stress Mining, Australian Centre for Geomechanics, Perth, Australia, 2002. 